\title{
Calibration and validation of SALTMED model under dry and wet year conditions using chickpea field data from Southern Portugal
}

\author{
L. L. Silva • R. Ragab • I. Duarte • E. Lourenço • \\ N. Simões $\cdot$ M. M. Chaves
}

Received: 31 January 2012/ Accepted: 25 April 2012

(C) Springer-Verlag 2012

\begin{abstract}
The SALTMED model is one of the few available generic models that can be used to simulate crop growth with an integrated approach that accounts for water, crop, soil, and field management. It is a physically based model using the well-known water and solute transport, evapotranspiration, and water uptake equations. In this paper, the model simulated chickpea growth under different irrigation regimes and a Mediterranean climate. Five different chickpea varieties were studied under irrigation regimes ranging from rainfed to $100 \%$ crop water requirements, in a dry and a wet year. The calibration of the model using one of the chickpea varieties was sufficient for simulating the other varieties, not requiring a specific calibration for each individual chickpea variety. The results of calibration and validation of the SALTMED model showed that the model can simulate very accurately soil moisture content, grain yield, and total dry biomass of different chickpea varieties, in both wet and dry years. This
\end{abstract}

Communicated by A. Kassam.

L. L. Silva $(\bowtie) \cdot$ E. Lourenço

Instituto de Ciências Agrárias e Ambientais Mediterrânicas

(ICAAM), Évora University, Apartado 94,

7002-554 Évora, Portugal

e-mail: 1lsilva@uevora.pt

R. Ragab

Centre for Ecology and Hydrology (CEH),

Wallingford OX10 8 BB, UK

I. Duarte $\cdot$ N. Simões

INRB, I.P./INIA, Elvas, Apartado 6,

7350-951 Elvas, Portugal

M. M. Chaves

Instituto de Tecnologia Química e Biológica (ITQB),

Apartado 127, 2781-901 Oeiras, Portugal new version of the SALTMED model (v. 3.02.09) has more features and possibilities than the previous versions, providing academics and professionals with a very good tool to manage water, soil, and crops.

\section{Introduction}

In regions with limited freshwater resources and increasing demand for food, agricultural water management becomes a key factor for a sustainable agriculture (WWAP 2012). Computer models that are able to simulate crop growth under different irrigation managements and strategies can be very useful tools to increase water use efficiency and productivity. These models can also be used to simulate crop performance in regions where some crops have not been grown before or when the growing conditions have changed. Sivakumar and Glinni (2002) presented, and briefly described, several crop growth models but most of them were single crop models or crop growth models for specific applications. These models can be very useful for a certain research objective, but cannot be used for more general conditions or for on-farm decisions. The extension services and farmers need models that can help them to make decisions such as what crop/variety to use, when to sow and harvest, when and how much to irrigate, what yield is expected under a specific irrigation system or strategy when using a certain water quality. Therefore, they prefer to have models with an integrated approach that accounts for water, crop, climate, soil and field management (Ragab et al. 2005a), and be able to work with different crops.

At present, there are not many models that can be used with a large variety of irrigation systems, soil types, soil stratifications, crops, and water management strategies. 